\title{
Experimental Study of a Bilinear Control for a GSHP Integrated
}

\author{
Air-conditioning System \\ Jiajia Gao ${ }^{\mathrm{a}}$, Gongsheng Huang ${ }^{\mathrm{b}}$, Xinhua $\mathrm{Xu}^{\mathrm{a}}$,* \\ ${ }^{a}$ Department of Building Environment \& Energy Engineering, Huazhong University of \\ Science \& Technology, Wuhan, China \\ ${ }^{\mathrm{b}}$ Department of Architecture and Civil Engineering, City University of Hong Kong, Kowloon, \\ Hong Kong, China \\ *Corresponding author, bexhxu@hust.edu.cn
}

\begin{abstract}
This paper presents an experimental study on a bilinear temperature control of a ground source heat pump (GSHP) integrated variable air volume (VAV) air-conditioning system, which may experience significant variations in the supply air temperature due to the frequent on/off switch of the ground source heat pump and the low thermal capacity at the air side. The bilinear control was realized in a building automation system (BAS) and applied to a test rig. The experimental results show that with an online estimation of the cooling load the bilinear control was able to maintain the space temperature at its set-point well and the control performance was superior to that of a conventional PI control. Therefore, the bilinear control has the potential to be used in GSHP integrated air-conditioning systems to improve the robustness and accuracy of the space temperature control.
\end{abstract}

Keyword: VAV air-conditioning system; Bilinear control; Robustness; Space temperature control 


\section{Introduction}

Building energy conservation and $\mathrm{CO}_{2}$ emission reduction are among the most important issues nowadays concerned by international communities (Pérez-Lombard et al. 2011; Cakır et al. 2012). According to the studies of Pérez-Lombard et al. (2008) and Shen and Lukes (2015), more than $40 \%$ of the energy consumed by buildings is used to maintain a good indoor environment for occupants. To improve building energy efficiency, an efficient way is to develop tools or systems to explore renewable energy. Ground source heat pump (GSHP) is such a system, which makes use of the 'heat' or 'cooling' stored inside the ground to reduce the electrical energy needed by the air-condition system of a building (Liu and Hong 2010; Corberan et al. 2011; Bayer et al. 2012).

A GSHP-integrated air-conditioning system is widely used for small-scale buildings (Zhao et al. 2003). In such a system, the produced cooling or heating will be used to condition the air through an air-handling unit (AHU) (a heat exchanger between air and water), and the conditioned air will be delivered by an air-distribution system to indoor space where cooling/heating is needed. The air-distribution system can be a constant-air-volume (CAV) or a variant-air-volume (VAV) system. As many studies have shown that a VAV system is more energy efficient than a CAV system (Aktacir et al. 2010; Xu et al. 2010), a VAV system is considered in this study. In a conventional VAV system, the supply air temperature is controlled to a constant (or a set-point) by adjusting the water flow rate inside the AHU and the indoor space temperature is maintained at a desired value by changing the supply air flow rate. As the space temperature process is not linear and the thermal load is time-varying, a number of advanced control strategies were developed in past decades, such as model-based predictive control (Yuan and Perez 2006; Morosan et al. 2010; Afram and Janabi-Sharifi 2014), fuzzy control (Rajagopalan et al 2008; Kaur and Kaur 2012; Yordanova et al 2015), 
robust infinite control (Andensor et al. 2008; Moradi et al 2012), and supervisory control (Nassif et al. 2005; Dounis and Caraiscos 2007).

In a small-scale GSHP integrated VAV system, the space temperature control is even more difficult. This is because the GSHP always use a simple on/off control to adjust the heating or cooling capacity supply according to instantaneous building demand in order to simplify the operation (Montagud et al. 2014). Due to the on/off capacity control, the supply air temperature cannot be controlled to a constant. If the cooling load is light and the thermal capacity at the air side is low, it may present a significant disturbance to indoor space temperature control. Therefore, a new control method was proposed to attenuate the influence of the GSHP on/off control on the space temperature control (Gao et al. 2015). The new method in (Gao et al. 2015) was titled as bilinear control. The bilinear control was theoretically developed by Huang (2011) to deal with the input-output nonlinearity, load uncertainty and operational constraints in a variable-air-volume (VAV) air-conditioning system. It is able to guarantee the asymptotic stability of the VAV system when the supply air temperature is relatively constant. As the supply air temperature in the GSHP integrated air-conditioning system cannot be maintained at a constant, the bilinear control developed by Huang (2011) was simplified by removing the check at each time instant whether the control signal satisfies the constraints under consideration or not. This simplification was tested in a simulation platform and until now no any experimental test has been reported.

This paper therefore presents an experimental study of the bilinear control algorithm in (Gao et al. 2015). This experimental study aims to validate the control performance of the bilinear control and discuss its application in the real GSHP integrated VAV air-conditioning system. The paper is organized as follows. At the beginning, a typical VAV air-conditioning system 
and the control algorithm are described. Then, a real building central air-conditioning system test platform is established for implementation and validation of the control algorithm. Finally, the results of experimental validation as well as the application issues are presented.

\section{Control Algorithm}

The zone temperature control system is shown in Fig. 1, where the inputs of the controller are the return air temperature (the zone temperature) $T_{z}$, the supply air temperature $T_{S}$ and the zone temperature set point $T_{z, \text { set }}$ and the output is the fan frequency $F$. The objective of the control is to maintain the zone temperature at its set point at different load conditions. To realize the control objective, a bilinear control algorithm was developed by the authors (Gao et al. 2015) based on the dynamic balance of the sensible heat of the space air as described by Eq. (1) (Underwood 1999; Yuan and Perez 2006; Huang 2011).

$$
C_{z} \frac{d T_{z}}{d t}=c_{a} \rho_{a} v_{s}\left(T_{s}-T_{z}\right)+q_{z}, \quad C_{z}=c_{a} \rho_{a} V_{z}
$$

where $C_{z}$ is the air thermal capacitance $\mathrm{kJ} / \mathrm{K}, c_{a}$ is the air specific heat $\mathrm{kJ} / \mathrm{kg} \cdot \mathrm{K}, \rho_{a}$ is the air density $\mathrm{kg} / \mathrm{m}^{3}, V_{z}$ is the space volume $\mathrm{m}^{3}$, and $q_{z}$ is the sensible cooling load of the zone $\mathrm{kW}$. It should be noted that $v_{s}$ is the input and $T_{z}$ is the output in Eq. (1), which describes a bilinear process due to the product term $\left(v_{s} \times T_{z}\right)$ in the right hand side term of Eq. (1) (Huang and Filip 2012).

<Fig. 1 Schematic diagram of the room temperature control system>

The bilinear control algorithm has three major tasks, including online estimating the zone cooling load $q_{z}$, calculating the required supply air flow rate $v_{s}$ and calculating the corresponding fan frequency $F$. 
The load is estimated by

$$
\hat{q}_{z, k}=\frac{1}{N_{w}}\left(\sum_{l=1}^{N_{w}} q_{z, k-l}\right)
$$

where $k$ is the time instant,

$$
q_{z, k-l}=c_{a} \rho_{a} v_{s, k-l}\left(T_{z, k-l}-T_{s, k-l}\right), l=1, \cdots, N_{w}
$$

Equation (3) is the principle of an energy meter, which is derived from Eq. (1) when $d T / d t$ approaches to zero. At the current step $k$, as $v_{k}$ is the variable to be decided and unknown, it is impossible to derive $q_{z, k}$ and hence the average cooling load measured at previous $N_{w}$ steps was used instead. The error between the actual cooling load and its estimation will cause bias in the zone temperature and its set point. However, when the load is stable, this bias will be insignificant according to previous simulation study (Gao et al. 2015).

The required supply air flow rate $v_{s, k}$ is calculated as follows. Firstly, Eq. (1) is discretized with a sampling interval $h$ as

$$
T_{z, k+1}=T_{z, k}+\alpha_{1} v_{s, k}\left(T_{s, k}-T_{z, k}\right)+\alpha_{2} \hat{q}_{z, k}
$$

where $\alpha_{1}=c_{a} \rho_{a} h / C_{z}$ and $\alpha_{2}=h / C_{z}$ and $q_{z, k}$ is replaced by $\hat{q}_{z, k}$. Define the tracking error as $e_{z, k}=T_{z, k}-T_{z, \text { set }}$, then the supply air flow rate is given

$$
v_{s, k}=\frac{(1-\gamma) e_{z, k}+\alpha_{2} \hat{q}_{z, k}}{\alpha_{1}\left(e_{z, k}+T_{z, s e t}-T_{s, k}\right)}
$$

where $\hat{q}_{z, k}$ is the estimated cooling load, and $\gamma$ is a user-defined parameter satisfying

$$
0<\gamma<1
$$

The stability analysis of the control law given by Eq. (5) should be referred to (Huang 2011).

The corresponding fan frequency $F_{k}$ is calculated by 


$$
F_{k}=\frac{\bar{F}}{a_{1}}\left(\frac{v_{s, k}}{\bar{v}_{s}}-a_{0}\right)
$$

where $\bar{F}$ is the rated frequency of the fan (usually $50 \mathrm{~Hz}$ ), $\bar{v}_{s}$ is the maximum flow rate corresponding to the rated frequency, and $a_{0}$ and $a_{1}$ are coefficients that should be identified by fitting the operational data of the fan at different frequency.

The control algorithm, which will be applied to a real test rig, is summarized as below:

\section{Initialization}

- Identify the fan model parameters $a_{0}$ and $a_{1}$ using the operational data of the fan;

- Define the room temperature set-point $T_{z, \text { set }}$, specify the user-defined parameter $\gamma$ inside the range specified by the inequality (6) and $N_{w}$;

- Estimate the maximal cooling load $\bar{q}_{z}$ of the zone and initialize the cooling load $q_{z, k-l}, l=1, \cdots, N_{w}$ as half of the maximum cooling load.

\section{At each sampling time}

- $\quad$ Estimate the real-time cooling load $\hat{q}_{z, k}$ by Eq. (2);

- Calculate the tracking error $e_{z, k}$ by $e_{z, k}=T_{z, k}-T_{z, \text { set }}$ and the required supply air flow rate $v_{\mathrm{s}, k}$ by Eq. (5);

- Calculate the supply air fan frequency $F_{k}$ by Eq. (7), and apply $F_{k}$ to the supply air fan. If $F_{k}$ is larger than its maximum allowable bound $\bar{F}, F_{k}=\bar{F}$; else if $F_{k}$ is smaller than its minimum allowable bound $\underline{F}, F_{k}=\underline{F}$;

- Update $q_{z, k-l}, l=0, \cdots, N_{w}-1$ and wait for the next sampling time.

\section{Experiment Facility}

\subsection{Description of the test rig}

The test rig of the GSHP integrated air-conditioning system, constructed in 2012, includes a 
building zone, a GSHP, water pumps, an AHU and a ground source heat exchanger (GSHE). The layout of the test rig is shown in Fig. 2. The north side of the room is an exterior wall; the east and south wall are interior walls; while the west interior wall is a partition of glass curtain. The walls are constructed with common brick and plaster on both sides. The ceiling of the room has a steel structure with insulation cover of foam glass. The main parameters of this room are listed in Table 1.

<Fig. 2 Layout of the GSHP integrated air-conditioning system>

<Table 1 Description of the conditioned zone >

The main devices of the GSHP-integrated air-conditioning system are located inside the equipment zone, and a picture of these devices is given in Fig. 3. The technique data of this system is summarized in Table 2 .

\section{<Fig. 3 Main components of the GSHP integrated air-conditioning system>}

$<$ Table 2 Technique data of the GSHP-integrated A/C system >

\subsection{BAS and the control program}

A building automation system (BAS), Alerton BACtalk BAS, is used to monitor and control the system, where the workstation of Envision is used for both the BACtalk server and clients. The global controller module is VLX; while the field controller module is VLCs, which is connected with sensors/actuators directly. The communication protocol is BACnet, which was developed by the American Society of Heating, Refrigerating and Air-Conditioning Engineers (ASHRAE). The technical data of the sensors and actuators installed in this system are listed in Table 3.

<Table 3 Description of sensor and actuator> 
As the logical modules in the Alerton BACtalk system cannot be used to code the bilinear control algorithm directly, Visual Basic (VB) is used to program the control algorithm and communicate with the Alerton BACtalk. The VB program is connected with the BAS through the interface of an ActiveX (formerly known as OLE). The communication process is shown as follows. Firstly, the link between the VB and the Alerton BACtalk is established by "BACtalk ActiveX Interface". Then, the real-time data such as the measured return air temperature and supply air temperature are read from a BACtalk Object using the function of "synGetpointdata" and sent to the VB program. With those data, the control algorithm coded using the VB language calculates control signals by Eq. (7) and sends the control signals to the BACtalk Object using the "synWritePoint" function.

It should be noted that the proposed control will be compared with a PI control, of which the control law is

$$
u_{k}=u_{k-1}+K_{p}\left(1+\frac{h}{2 T_{i}}\right) e_{z, k}+K_{p}\left(\frac{h}{2 T_{i}}-1\right) e_{z, k-1}
$$

where the input is the space room temperature tracking error $e_{z, k}$; the control signal $u_{k}$ is the fan frequency; $K_{p}$ is the control gain; and $T_{i}$ is the integral time. The control algorithm was also coded using the VB language and communicated with the BAS using the "BACtalk ActiveX Interface”.

When the PI controller was tuned, the controlled process was assumed to be modeled as a first-order and time-delay process (Seborg et al 1989, Xu et al 2004), which can be given in the following form

$$
G(s)=\frac{K}{T s+1} e^{-\tau s}
$$

where, $G(s)$ is the transfer function of the process dynamics in the Laplace domain, $K$ is the steady-state gain, $T$ is the time constant, $\tau$ is the pure delay time of process response. A technique of graphical fitting of the first-order model using the step test was utilized to 
determine the unknown process parameters. Then, the PI control parameters $K_{p}$ and $T_{i}$ can be calculated based on the process parameters as follows (Seborg et al 1989)

$$
\begin{gathered}
K_{p}=\frac{0.9 T}{K \tau} \\
T_{i}=3 \tau
\end{gathered}
$$

\section{Experimental Results and Analysis}

\subsection{Load profile}

As the proposed control was compared with the PI control, the load profile for each control was tied to maintain as the same. Generally the cooling load of the room (only sensible heat load is concerned) has two parts: the external load due to the external gain and the internal load due to the internal gain. The former is mainly determined by the external air condition and solar gain, which are uncontrollable; while the latter is mainly determined by people's occupancy and equipment's heat emission, which can be roughly kept to be same during this experiment. Therefore, to avoid the uncontrollable load difference the experiment was carried out in the night from 19:00 to 21:30 (19:00 to 20:00 for the bilinear control and 20:20 to 21:20 for the PI control), during which the external cooling load was relatively stable. On the other hand, in order to test these two controls under various load conditions, the internal load was regulated using an adjustable electrical heater, which was adjusted every ten minutes as shown in Fig. 4. Except the load from the adjustable electrical heater, the interior lighting and the equipment contributed to the load as well. Estimated according to the rated power of the lighting and the equipment, this type of load was about $0.6 \mathrm{~kW}$. There was no occupancy in the air-conditioning zone during the tests.

<Fig. 4 Heat output profile of the heater> 


\subsection{Control performance evaluation of the bilinear control algorithm}

The sampling interval of 15 seconds was used for both the bilinear control and the PI control. For the bilinear control, the parameter $\gamma$ was set as $\gamma=0.6 ; N_{w}$ was set as $N_{w}=5$. Based on the annual load condition, the upper bound was set as $\bar{q}_{z}=11 \mathrm{~kW}$. The coefficients of the fan model (see Eq. (7)) were identified as $a_{0}=-0.0197$ and $a_{1}=1.0316$ by fitting the data of the measured air flow rate at different frequency. The CHWR temperature set-point was set as $15^{\circ} \mathrm{C}$, and the bandwidth of CHWR temperature control was $\pm 3^{\circ} \mathrm{C}$.

Fig. 5 illustrates the on/off operation of the GSHP and the variation of the supply air temperature accordingly. This variation was significant. The maximum was larger than $18{ }^{\circ} \mathrm{C}$, while the minimum was less than $12{ }^{\circ} \mathrm{C}$. Fig. 6 shows the space air temperature variations. It can be seen that the proposed control was able to maintain the space air temperature close to its set-point although the supply air temperature varied significantly. The average absolute tracking error at steady state was not larger than $0.1{ }^{\circ} \mathrm{C}$. Fig. 7 plots the fan frequency. The fan frequency increased when the supply air temperature increased and vice versa.

\section{$<$ Fig. 5 Variation of supply air temperature with GSHP on/off operation> \\ <Fig. 6 Control performance of the space air temperature> \\ <Fig. 7 Variation of the fan operating frequency $>$}

Fig. 8(a) shows the variations of the CHWR temperature. The CHWR temperature varied between $11^{\circ} \mathrm{C}$ and $19^{\circ} \mathrm{C}$ with the on/off of the GSHP, which was slightly different from the predefined range (i.e. $12{ }^{\circ} \mathrm{C}$ to $18{ }^{\circ} \mathrm{C}$ ). This difference may be caused by the inertia in the system dynamics. Fig. 8(b) illustrates the variations of the CHWS temperature. Again, these variations were closely related to the on/off the GSHP. 
<Fig. 8 Variation of the chilled water return/supply temperature>

The performance of the PI control is also shown in Figs. 6-8, where the control gain of the PI control was $K_{p}=0.8$ and the integral time was $T_{i}=2 \mathrm{~s}$. These two control parameters were tuned at the load condition of about $5.5 \mathrm{~kW}$, which was the load when the electrical heater was adjusted to the maximum value. This load is most close to the full load condition in this experiment. Compared with the proposed bilinear control, the PI control led to heavier oscillations in the space air temperature and more frequent on/off switch of the GHSP. The average absolute tracking error at steady state was around $0.2^{\circ} \mathrm{C}$. Besides, the fan operation frequency experienced much sharper variations when compared with the bilinear control. Same observations were also found in the chiller water return/supply temperature. Therefore, the bilinear control can achieve a better control performance in the GSHP-integrated air-conditioning system.

The efficiency of the load prediction (by Eq. 2) was also evaluated in the experiment. Fig. 9 presents the comparison of the estimated cooling load and the load calculated using the software of EnergyPlus. It can be seen that the difference was not significant. The average absolute error was $0.34 \mathrm{~kW}$, less than $7 \%$ when compared to the average cooling load. The cooling load estimation was used in the bilinear control and improved the space temperature control performance.

$<$ Fig. 9 Comparison of the actual cooling load and the estimated cooling load $>$ $<$ Fig 10 Control performance of the bilinear control with different $\gamma$ values $>$

The proposed control has a user-defined parameter $\gamma$. The selection of $\gamma$ is limited in its feasible range described by Eq. (6). As discussed in (Huang 2011), a larger $\gamma$ leads to a slow response of the controller, while a smaller one leads to a fast response of the controller. This 
was also validated in the experiment. Fig. 10 compares the control performance when $\gamma$ was set to be 0.4 to the case when $\gamma=0.6$. It shows that the control algorithm with $\gamma=0.4$ had a faster response. The settling time was 225 seconds; while it was 345 seconds when $\gamma=0.6$.

\subsection{Energy performance evaluation of the bilinear control algorithm}

The energy performance of the bilinear control was also compared with that of the PI control. The energy consumption of the system in one hour was listed in Table 4. Comparing with the PI control, the energy consumption of the fan in one hour was reduced by $0.247 \mathrm{kWh}$ (or $36.57 \%$ ). This is because when the bilinear control was used, the fan frequency changed smoothly and avoided the maximum value (i.e., the rated frequency of $50 \mathrm{~Hz}$ ) as shown in Fig. 7. The energy consumption of the GSHP in one hour was slightly increased by 0.069 $\mathrm{kWh}(2.45 \%)$ in the bilinear control. This is because the average CHWR temperature was 14.9 ${ }^{\circ} \mathrm{C}$ in the bilinear control; while it was $15.2{ }^{\circ} \mathrm{C}$ when the PI control was used. The total energy consumption of the system was still reduced by $0.177 \mathrm{kWh}(4.17 \%$ of the total energy consumption). The results show that the bilinear control can slightly improve the energy efficiency of the system, especially the energy efficiency of the fan.

$<$ Table 4 Energy consumption in one hour with different controllers $>$

\section{Application Issues}

This study also shows that the algorithm can be easily coded and realized in the BAS system as 'build-in' control components with powerful computational capacity have now gained widely ranging applications in modern buildings. These three inputs, including the measured space temperature $T_{z}$, the measured supply air temperature $T_{S}$ and the estimated sensible cooling load $\hat{q}_{z, k}$, are readily available in most BAS systems. The coefficients of the fan model can be identified by using the operational data of the fan at different frequency. 
Compared with a PID control only parameter $\gamma$ should be tuned and its feasible range is between 0 and 1 . The basic rule is that a large $\gamma$ leads to a less aggressive response to the disturbances in the load and the supply air temperature and a smaller one leads to a more aggressive response. $\gamma$ is suggested to be around 0.5 according to the experimental study.

The simplified bilinear control algorithm has been well applied to a GSHP integrated air-conditioning system even though the on/off switch of the GSHP results significant variations in the chilled water supply temperature and in the supply air temperature (from an air-handling unit) as well as in the room cooling load. This indicates that the proposed method has a good robustness to these variations. It is expected that when the supply air temperature varies less significantly (that is the case in most VAV systems using chiller plants, where the chilled water supply temperature is well maintained at a constant set point) the control stability of the room temperature should be even better. Therefore, the proposed method will find applications in many VAV systems.

It is worth to mention that multiple VAV boxes may be installed for air-conditioning in large-scale rooms. When those VAV boxes are controlled independently and the control zones (where the area served by a single VAV boxes is considered as a zone) are not separated by any partition, thermal coupling between zones may affect the control performance. As large-scale rooms are widely used as lecture theaters, conference hall, shopping mall, comprehensive study is needed, which will be our future work.

\section{Summary and Conclusion}

This paper presents an experimental study of the bilinear control developed by the authors in their previous work to validate its control performance and discuss its practicability. The 
control performance of the bilinear control was tested when it was applied to a test rig of a GSHP integrated air-conditioning system to control the space temperature of the case room. The control algorithm was realized in a BAS system, coded using the VB program and communicated with the system using BACnet. The experimental results show that the bilinear control can maintain the space air temperature at its set-point very well although the supply air temperature experienced significant variation. Comparing with the conventional PI control, the bilinear control is more robust as under the significant variations of the supply air temperature, the average absolute tracking error of the space temperature was much smaller than that of the PI control. The experimental study working also shows that the bilinear control algorithm can be easily coded and realized in the BAS system, and it can be easily used in a real VAV air-conditioning system, especially when a BAS is available.

\section{Acknowledgements}

This work presented in this paper is financially supported by a grant (No. 51178201) of National Science Foundation of China and supported by the research fund of "Program for New Century Excellent Talents in University" (No. 2011CDB292) as well as a grant (No. 20120142110078).

\section{References}

[1] Pérez-Lombard L., Ortiz J., Coronel J.F., Maestre I.R. (2011). A review of HVAC systems requirements in building energy regulations. Energy Build. 43(2):255-268.

[2] Cakır U., Comakli K. and Yüksel F. (2012). The role of cogeneration systems in sustainability of energy. Energy Convers. Manag. 63:196-202.

[3] Pérez-Lombard L., Ortiz J., Pout C. (2008). A review on buildings energy consumption information. Energy Build. 40(3):394-398. 
[4] Shen P., Lukes J. R. (2015). Impact of global warming on performance of ground source heat pumps in US climate zones. Energy Convers. Manag. 101:632-643.

[5] Liu X., Hong T. (2010). Comparison of energy efficiency between variable refrigerant flow systems and ground source heat pump systems. Energy and Build. 42:584-589.

[6] Corberan J.M., Finn D.P., Montagud C.M., Murphy F.T., Edwards K.C. (2011). A quasi-steady state mathematical model of an integrated ground source heat pump for building space control. Energy Build. 43:82-92.

[7] Bayer P., Saner D., Bolay S., Rybach L., Blum P. (2012). Greenhouse gas emission savings of ground source heat pump systems in Europe: A review. Renew. Sust. Energ. Rev. 16(2):1256-1267.

[8] Zhao L., Zhao L.L., Zhang Q., Ding G.L. (2003). Theoretical and basic experimental analysis on load adjustment of geothermal heat pump systems. Energy Convers. Manag. 44(1):1-9.

[9] Aktacir M. A., Büyükalaca O., Y1lmaz T. (2010). A case study for influence of building thermal insulation on cooling load and air-conditioning system in the hot and humid regions. Appl. Energy. 87(2):599-607.

[10] Xu X.H., Wang S.W. and Huang G.S. (2010). Robust MPC for temperature control of air-conditioning systems concerning on constraints and multi-type uncertainties. Build. Ser. Eng. Res. Technol. 31(1):39-55.

[11] Yuan S., Perez R. (2006). Multiple-zone ventilation and temperature control of a single-duct VAV system using model predictive strategy. Energy Build. 38:1248-1261.

[12] Morosan P.D., Bourdais R., Dumur D., Buisson J. (2010). Building temperature regulation using a distributed model predictive control. Energy Build. 42:1445-1452.

[13] Afram A., Janabi-Sharifi F. (2014). Theory and applications of HVAC control systems-A review of model predictive control (MPC). Build. Environ. 72:343-355. 
[14] Rajagopalan P., Rajasekaran K., Alagarsamy S., Iniyan S., Lal M.D. (2008). Experimental analysis of fuzzy controlled energy efficient demand controlled ventilation economizer cycle variable air volume air conditioning system. Therm. Sci. 12(3):15-32.

[15] Kaur A., Kaur A. (2012). Development of neuro fuzzy controller algorithm for air conditioning system. Int. J. Eng. Sci. 4(4):1667-1671.

[16] Yordanova S., Merazchiev D., Jain L. (2015). A two-variable fuzzy control design with application to an air-conditioning system. IEEE Trans. Fuzzy Syst. 23(2):474-481.

[17] Anderson M., Buehner M., Young P., Hittle D., Anderson C., Tu. J. and Hodgson D. (2008). MIMO robust control of HVAC systems. IEEE Trans. Control Syst. Technol. 16:475-483.

[18] Moradi H., Bakhtiari-Nejad F., Saffar-Avval M. (2012). Multivariable robust control of an air-handling unit: A comparison between pole-placement and $\mathrm{H} \infty$ controllers. Energy Convers. Manag. 55:136-148.

[19] Nassif N., Kajl S., Sabourin R. (2005). Optimization of HVAC control system strategy using two-objective genetic algorithm. HVAC\&R Res. 11(3):459-486.

[20] Dounis A.I., Caraiscos C. (2007). Intelligent coordinator of fuzzy controller-agents for indoor environment control in buildings using 3-d fuzzy comfort set. In: 2007 IEEE international conference on fuzzy systems.

[21] Montagud C., Corberan J.M., Montero A. (2014). In situ optimization methodology for the water circulation pumps frequency of ground source heat pump systems. Energy Build. 68:42-53.

[22] Gao J.J., Huang G.S., Xu X.H. (2015). Space temperature control of a GSHP-integrated air-conditioning system. Energy Build. 108:127-136.

[23] Huang G.S. (2011). Model predictive control of VAV zone thermal systems concerning 
bi-linearity and gain nonlinearity. Control Eng. Pract. 19:700-710.

[24] Underwood C.P. (1999), HVAC control systems: modelling, analysis and design. London \& New York: E\&RN Spon.

[25] Huang G.S. and Filip J. (2012). Model-based robust temperature control for VAV air-conditioning system. HVAC\&R Res. 18(3):432-445.

[26] Seborg D.E., Edgar T.F., Mellichamp D.A. (1989). Process dynamic and control. New York: John Wiley \& Sons.

[27] Xu X.H., Wang S.W., Shi W.Z. (2004). A robust sequencing control strategy for air-handling units. Building Serv. Eng. Res. Technol., 25(2): 141-158. 
Fig. 1 Schematic diagram of the room temperature control system

Fig. 2 Layout of the GSHP integrated air-conditioning system

Fig. 3 Main components of the GSHP integrated air-conditioning system

Fig. 4 Heat output profile of the heater

Fig. 5 Variation of supply air temperature with GSHP on/off operation

Fig. 6 Control performance of the space air temperature

Fig. 7 Variation of the fan operating frequency

Fig. 8 Variation of the chilled water return/supply temperature

Fig. 9 Comparison of the actual cooling load and the estimated cooling load

Fig. 10 Control performance of the bilinear control with different $\gamma$ values 


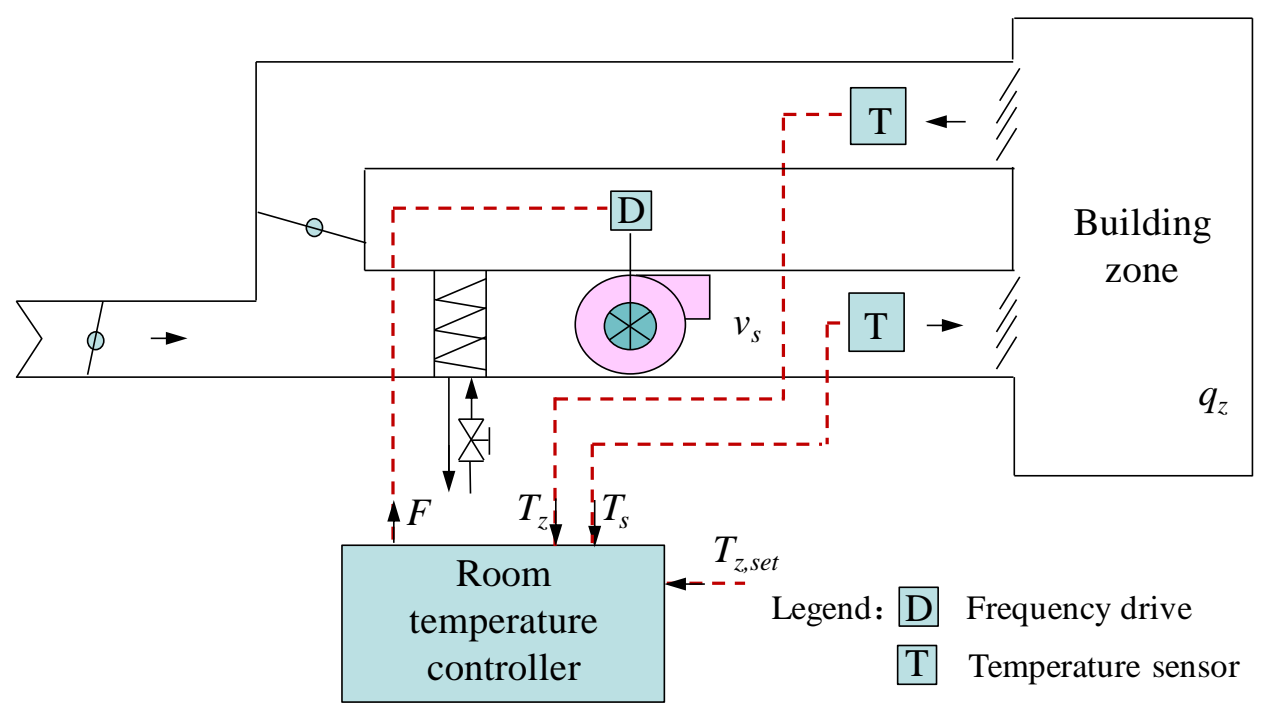

Fig. 1 Schematic diagram of the room temperature control system

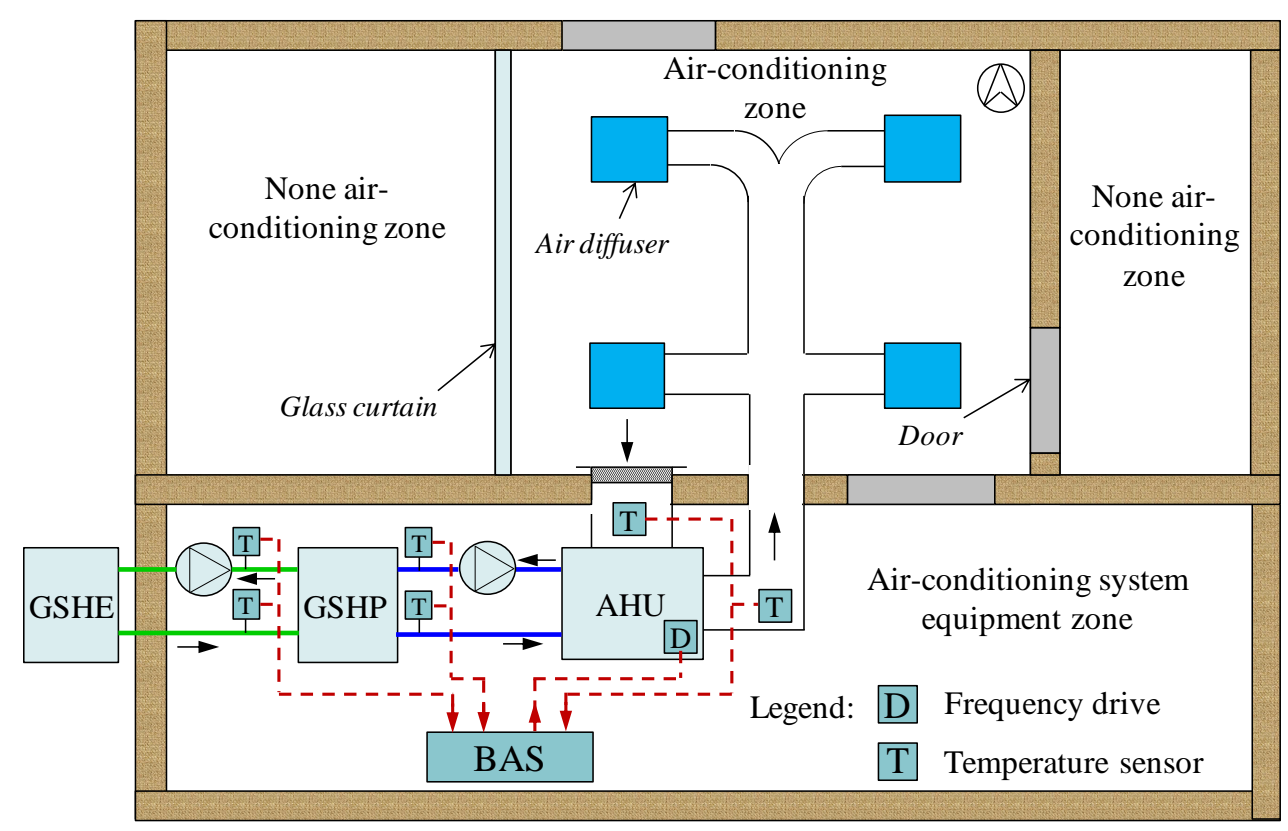

Fig. 2 Layout of the GSHP integrated air-conditioning system 


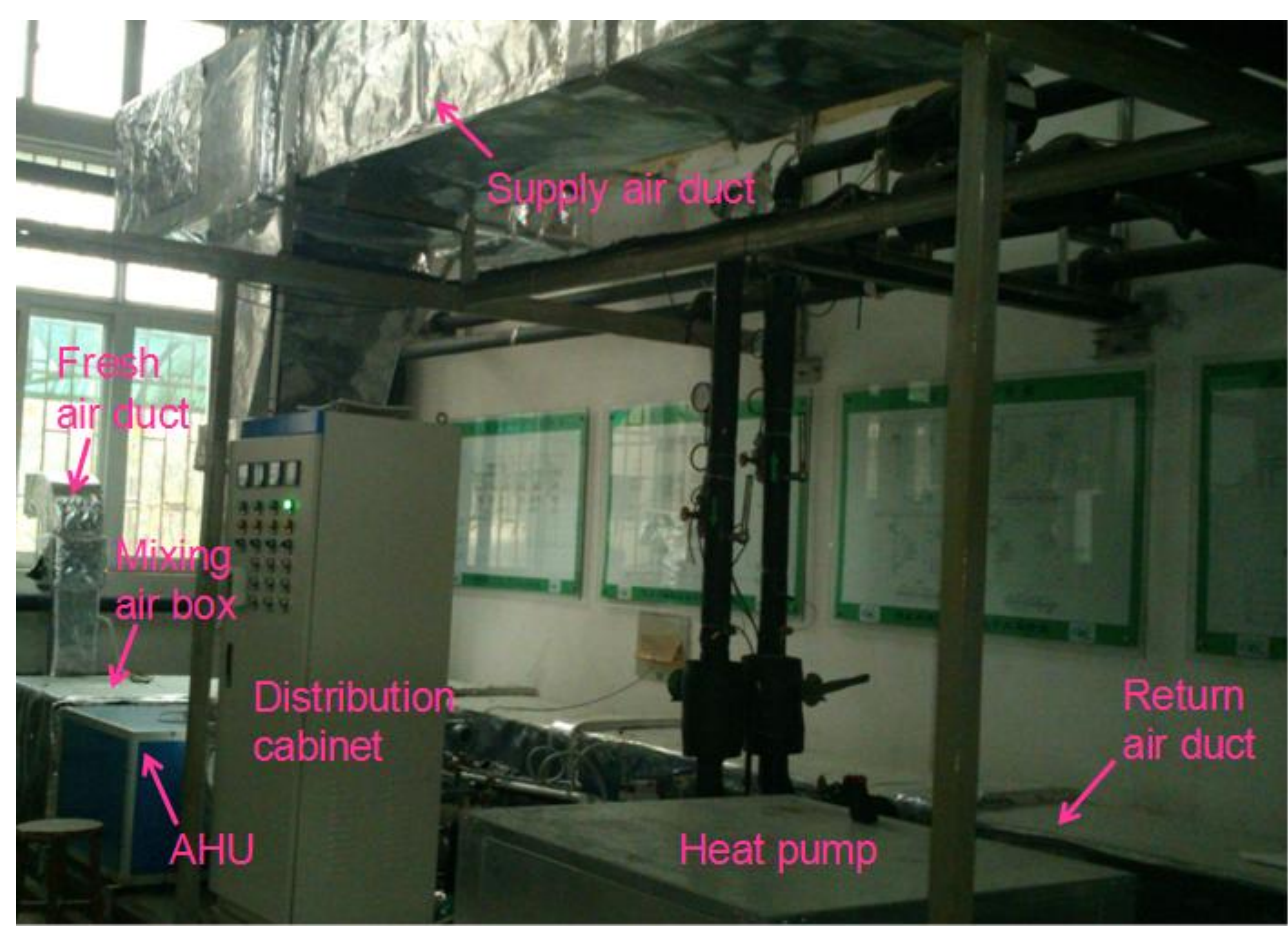

Fig. 3 Main components of the GSHP integrated air-conditioning system

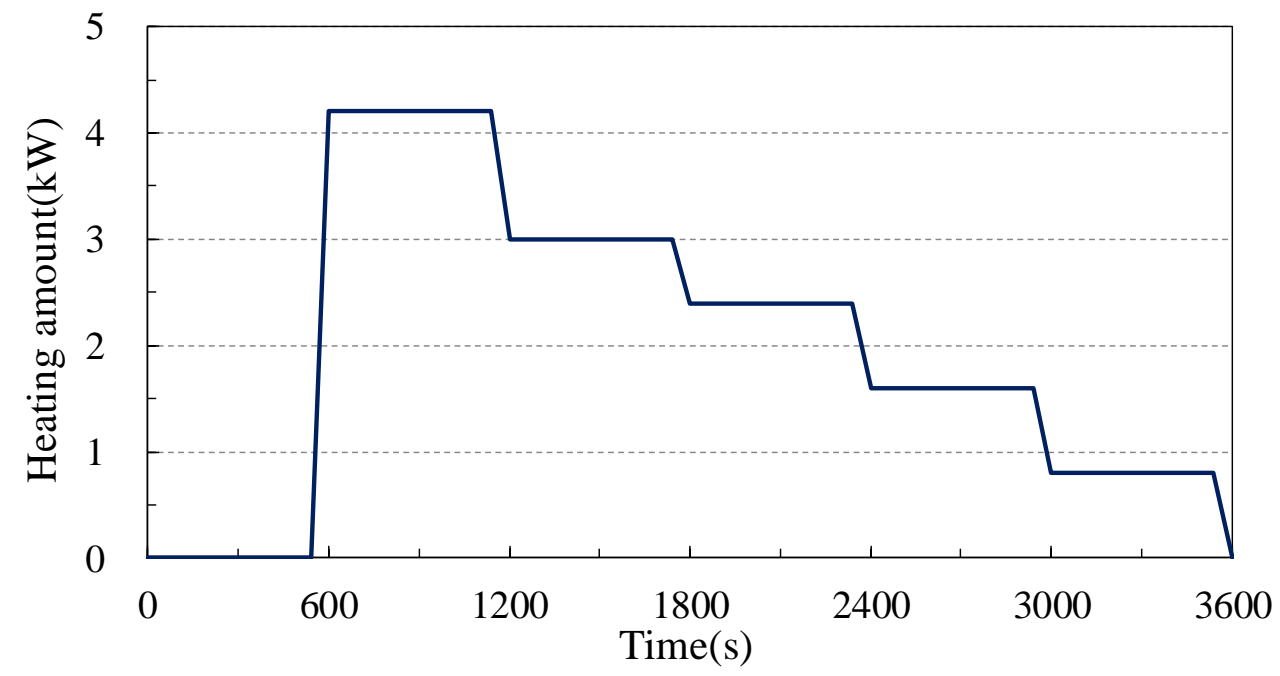

Fig. 4 Heat output profile of the heater 


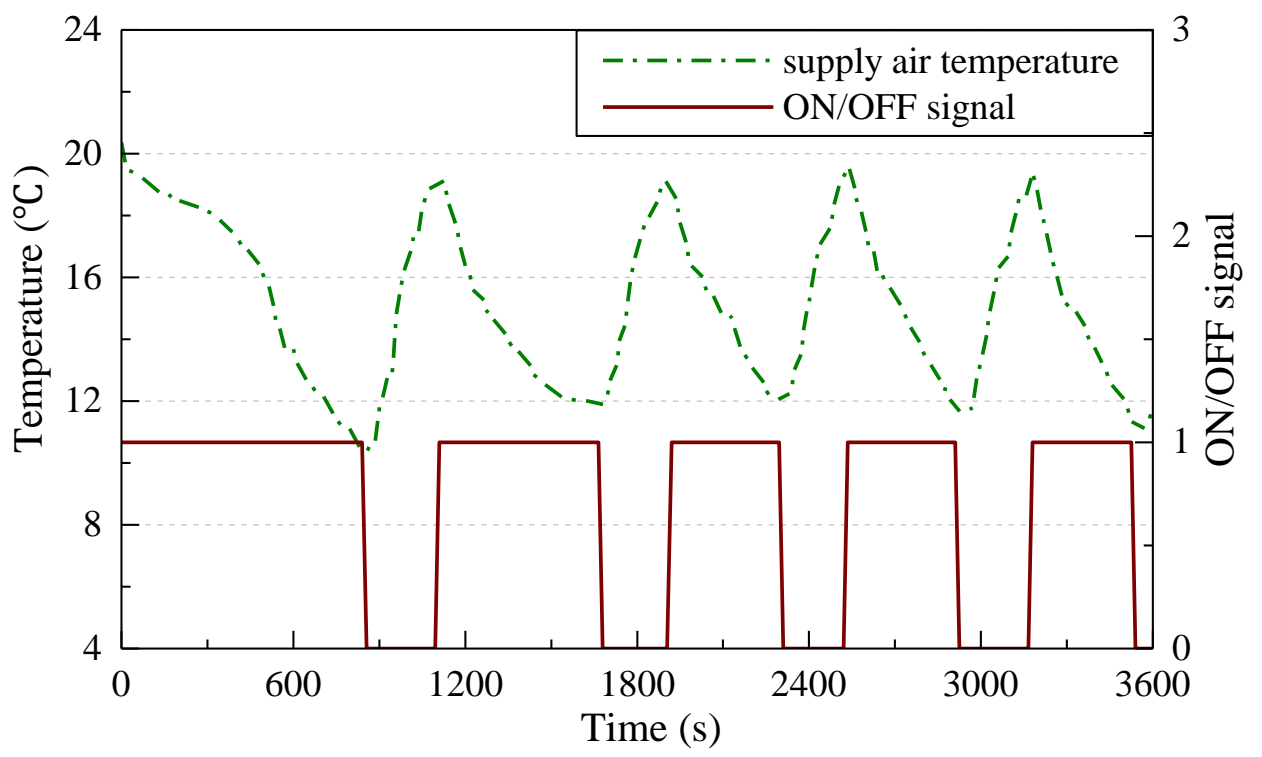

Fig. 5 Variation of supply air temperature with GSHP on/off operation

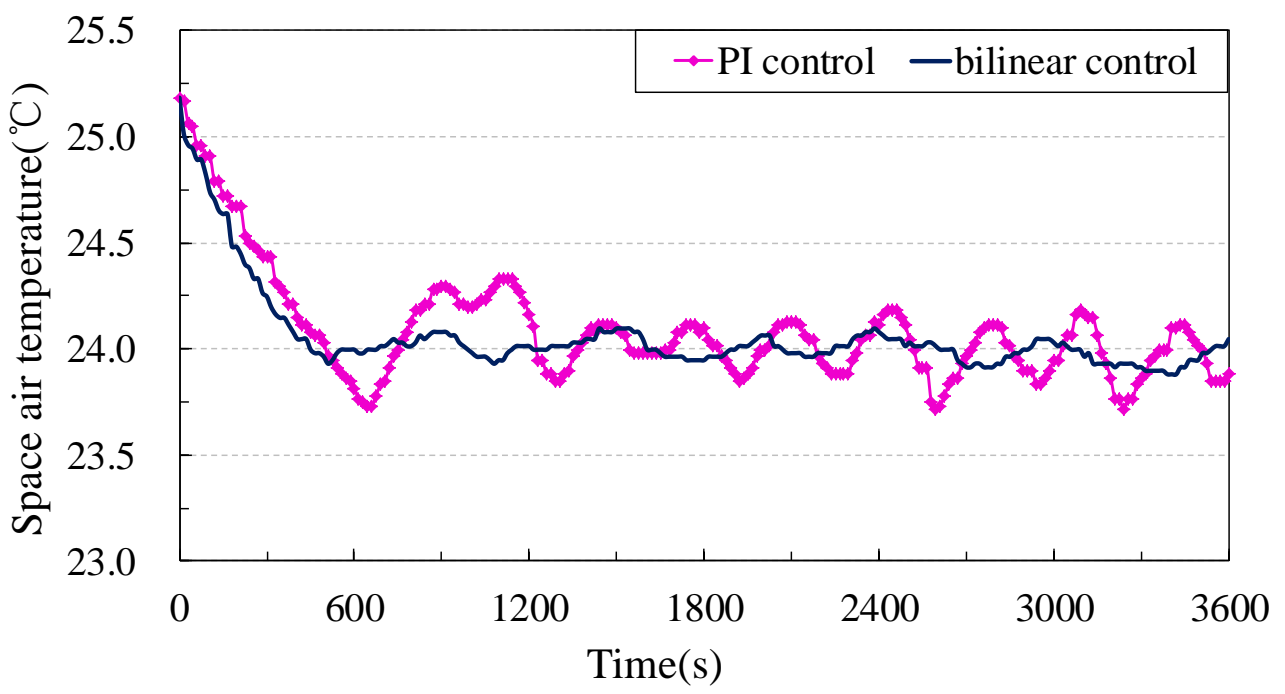

Fig. 6 Control performance of the space air temperature 


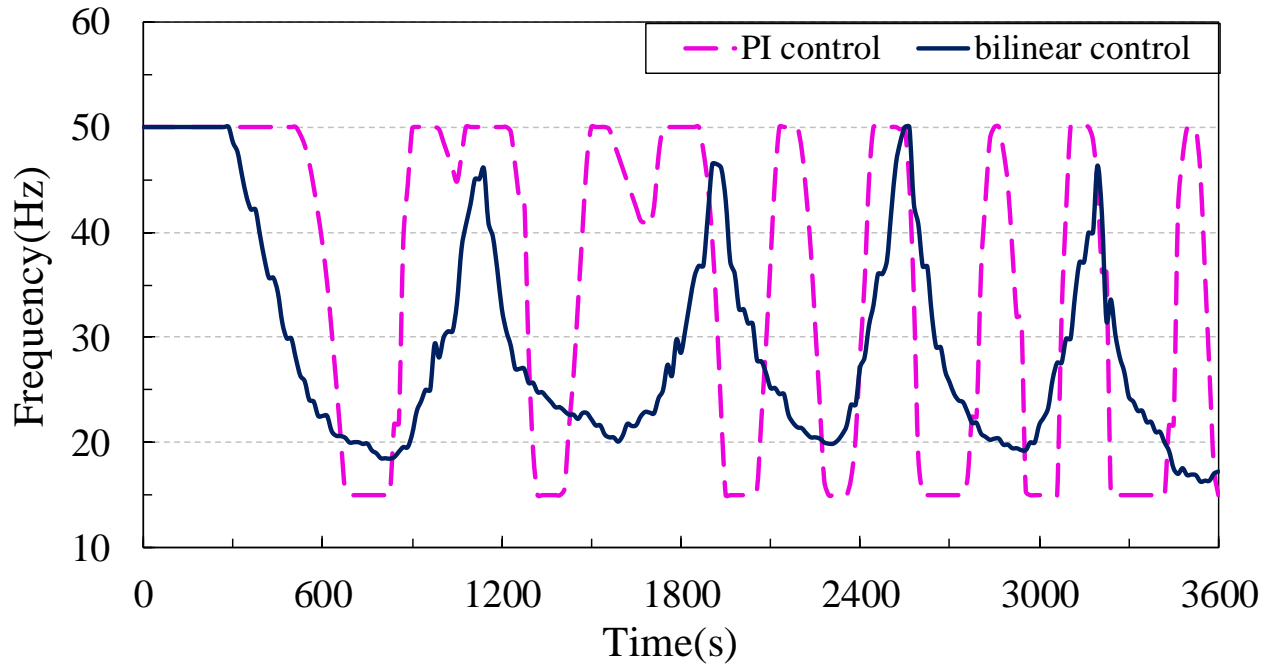

Fig. 7 Variation of the fan operating frequency 


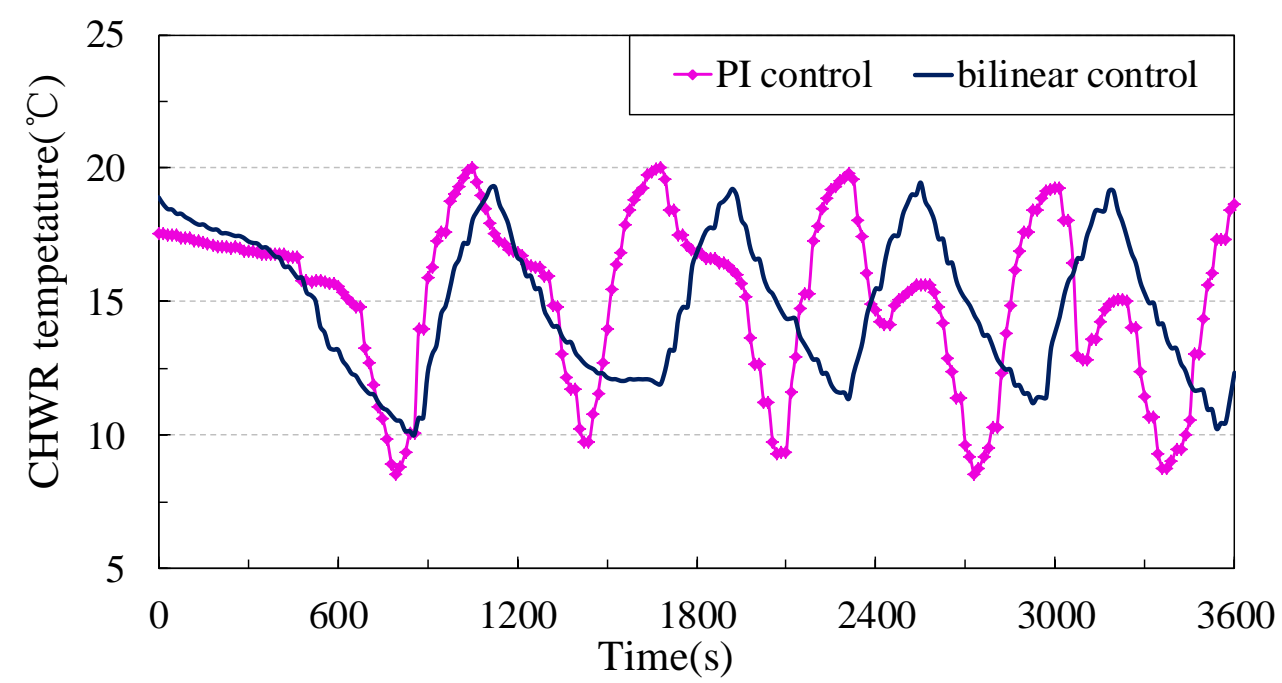

(a) Variations of the CHWR temperature

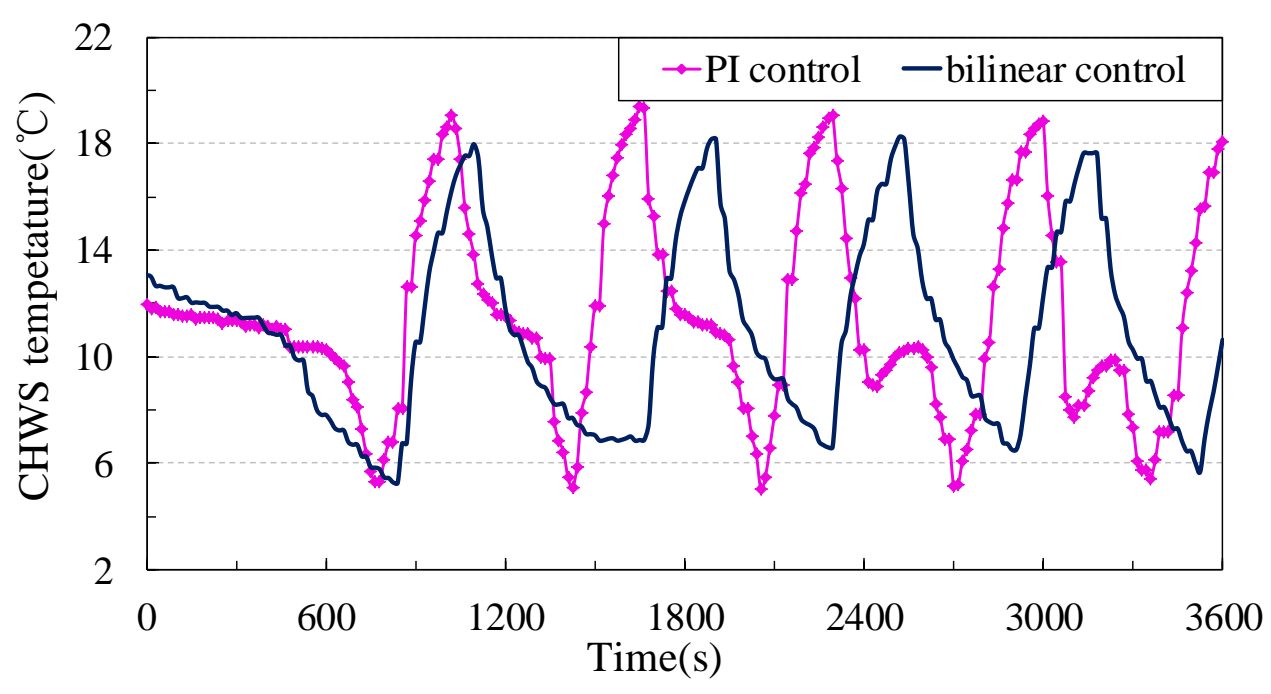

(b) Variations of the CHWS temperature

Fig. 8 Variation of the chilled water return/supply temperature 


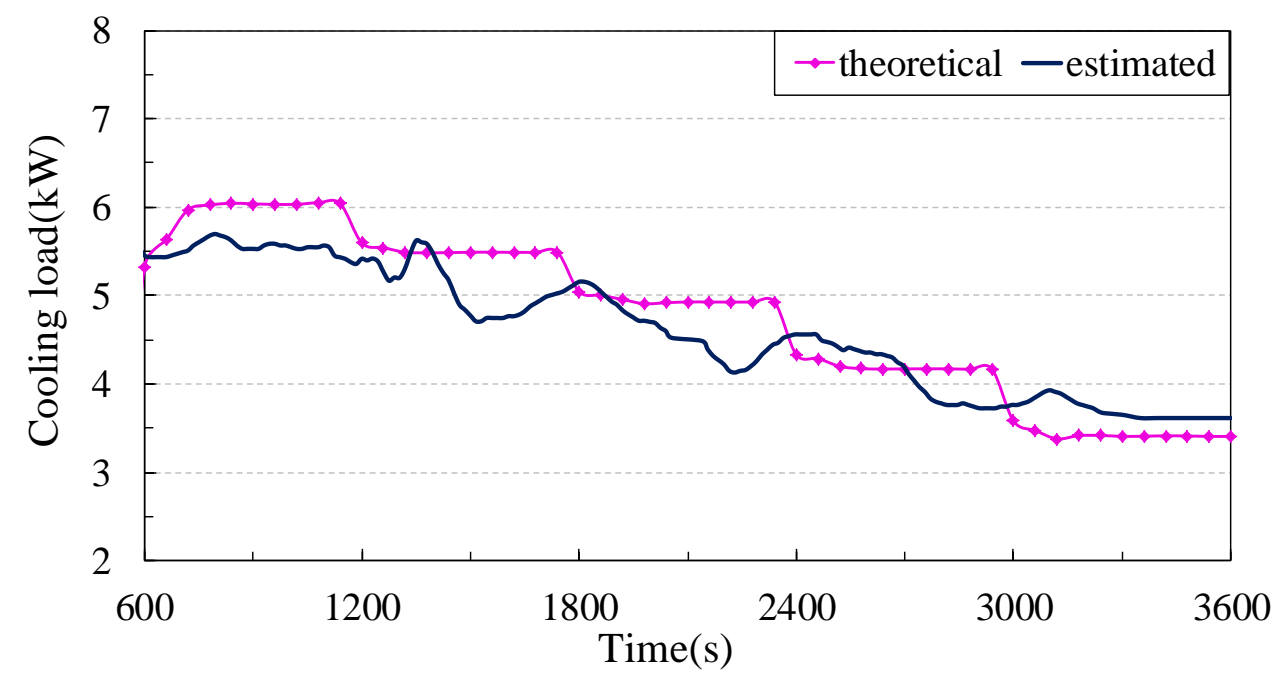

Fig. 9 Comparison of the actual cooling load and the estimated cooling load

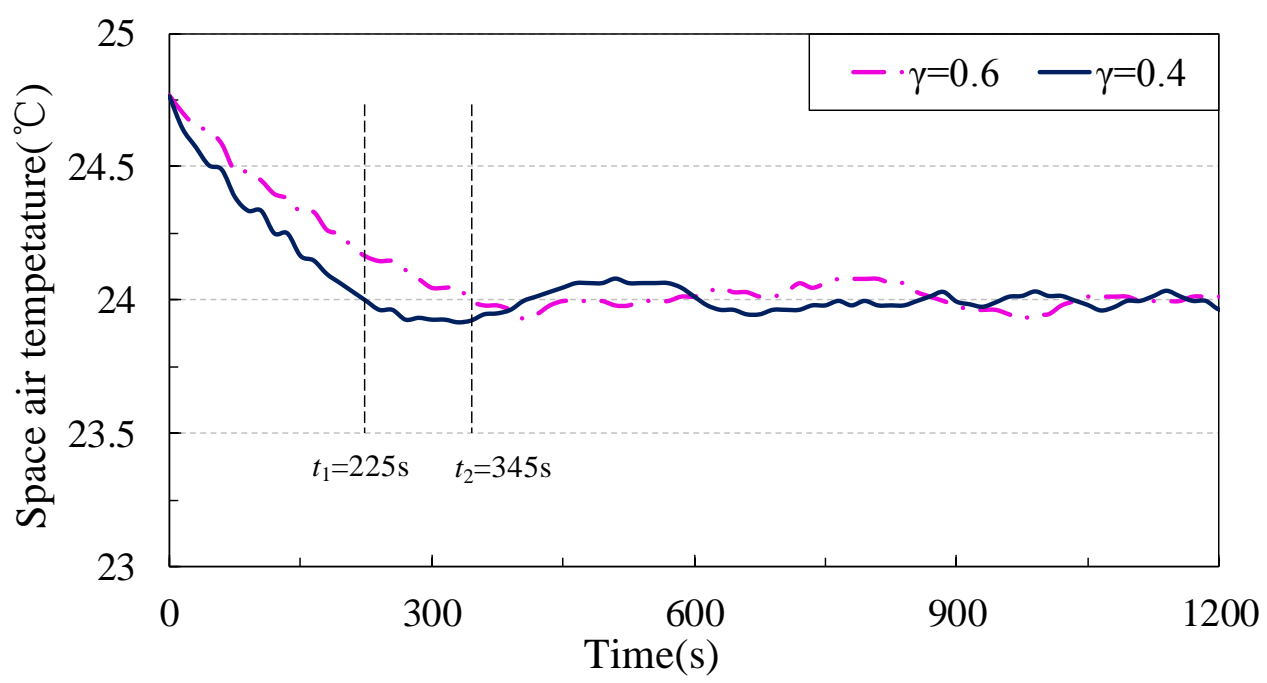

Fig. 10 Control performance of the bilinear control with different $\gamma$ values 
Table(s) with Caption(s)

Table 1 Description of the conditioned zone

Table 2 Technique data of the GSHP-integrated A/C system

Table 3 Description of sensor and actuator

Table 4 Energy consumption in one hour with different controllers 
Table 1 Description of the conditioned zone

\begin{tabular}{lccc}
\hline \multicolumn{1}{c}{ Parameters } & Size & $\begin{array}{c}\text { Thermal capacity } \\
\left(\mathrm{J} /\left(\mathrm{m}^{2} \cdot \mathrm{K}\right)\right)\end{array}$ & $\begin{array}{c}\text { Thermal conductance } \\
(\mathrm{W} /(\mathrm{m} \cdot \mathrm{K}))\end{array}$ \\
\hline Utilization of zone (building) & Lab & - & - \\
Type of HVAC system & Single duct AHU & - & - \\
Zone dimension $(\mathrm{L} \times \mathrm{W} \times \mathrm{H})$ & $6.7 \times 6.9 \times 3.5 \mathrm{~m}^{3}$ & - & - \\
North side wall size $(\mathrm{W} \times \mathrm{H})$ & $6.9 \times 3.5 \mathrm{~m}^{2}$ & - & - \\
North side door size $(\mathrm{W} \times \mathrm{H})$ & $1.8 \times 2.0 \mathrm{~m}^{2}$ & - & - \\
East side door size $(\mathrm{W} \times \mathrm{H})$ & $1.4 \times 2.0 \mathrm{~m}^{2}$ & - & - \\
South side door size $(\mathrm{W} \times \mathrm{H})$ & $1.5 \times 2.0 \mathrm{~m}^{2}$ & - & - \\
West side glass curtain $(\mathrm{L} \times \mathrm{H})$ & $6.7 \times 3.5 \mathrm{~m}^{2}$ & - & - \\
Steel structure floor size $(\mathrm{L} \times \mathrm{W})$ & $6.7 \times 6.9 \mathrm{~m}^{2}$ & - & 0.93 \\
Wall material & & & 0.814 \\
-- Layer 1 plaster thickness & $0.01 \mathrm{~m}$ & 13392 & 0.93 \\
-- Layer 2 brick thickness & $0.24 \mathrm{~m}$ & 379728 & - \\
-- Layer 3 plaster thickness & $0.02 \mathrm{~m}$ & 26784 & 58.15 \\
Glass curtain thickness & $0.012 \mathrm{~m}$ & - & 0.058 \\
Steel structure thickness & $0.02 \mathrm{~m}$ & 75674 & - \\
Insulation cover thickness & $0.03 \mathrm{~m}$ & 3528 & - \\
\hline
\end{tabular}


Table 2 Technique data of the GSHP-integrated A/C system

\begin{tabular}{|c|c|}
\hline \multicolumn{2}{|c|}{ GSHP } \\
\hline Compressor type & Scroll compressor \\
\hline Evaporator, condenser type & Tube-in-tube heat exchangers \\
\hline Expansion value & A common thermostatic expansion valve \\
\hline Refrigerant & $\mathrm{R} 22$ \\
\hline Rated cooling capacity & $17.2 \mathrm{~kW}$ \\
\hline Rated input power & $3.91 \mathrm{~kW}$ \\
\hline Rated CHWR temperature set-point & $12{ }^{\circ} \mathrm{C}$ \\
\hline $\begin{array}{l}\text { Rated band width of the CHWR } \\
\text { temperature control band }\end{array}$ & $\pm 3{ }^{\circ} \mathrm{C}$ \\
\hline Rated chilled water flow & $0.822 \mathrm{~kg} / \mathrm{s}$ \\
\hline Rated cooling water flow & $1.006 \mathrm{~kg} / \mathrm{s}$ \\
\hline Chilled water pump rated power & $0.292 \mathrm{~kW}$ \\
\hline Cooling water pump rated power & $0.475 \mathrm{~kW}$ \\
\hline \multicolumn{2}{|c|}{ Air-handling unit } \\
\hline Rated air flow rate & $3000 \mathrm{~m}^{3} / \mathrm{h}$ \\
\hline Supply air fan rated power & $1.1 \mathrm{~kW}$ \\
\hline Supply air fan frequency & $15 \mathrm{~Hz}$ to $50 \mathrm{~Hz}$ \\
\hline
\end{tabular}


Table 3 Description of sensor and actuator

\begin{tabular}{lccc}
\hline \multicolumn{1}{c}{ Sensor/Actuator } & signal type & Range & Accuracy \\
\hline Air temperature sensor & $10 \mathrm{~K} \mathrm{ohm}$ & $0-70{ }^{\circ} \mathrm{C}$ & $\pm 0.1^{\circ} \mathrm{C}$ \\
water temperature sensor & $4-20 \mathrm{~mA}$ & $0-50{ }^{\circ} \mathrm{C}$ & $\pm 0.1^{\circ} \mathrm{C}$ \\
Fan frequency drive & $0-10 \mathrm{~V}$ & $0-50 \mathrm{~Hz}$ & - \\
Heat pump power meter & RS-485 & $0-10 \mathrm{~kW}$ & $\pm 0.5 \%$ \\
Water pump power meter & RS-485 & $0-1 \mathrm{~kW}$ & $\pm 0.5 \%$ \\
Fan power meter & RS-485 & $0-2 \mathrm{~kW}$ & $\pm 0.5 \%$ \\
\hline
\end{tabular}


Table 4 Energy consumption in one hour with different controllers

\begin{tabular}{lccc}
\hline \multirow{2}{*}{ Equipment } & \multicolumn{2}{c}{ Energy consumption (kWh) } & $\begin{array}{c}\text { Energy } \\
\text { saving }(\%)\end{array}$ \\
\cline { 2 - 3 } & PI control & bilinear control & 36.57 \\
Fan & 0.676 & 0.429 & - \\
Chilled water pump & 0.295 & 0.296 & - \\
Cooling water pump & 0.482 & 0.482 & -2.45 \\
Heat pump & 2.811 & 2.880 & $\mathbf{4 . 1 7}$ \\
Overall system & 4.264 & 4.087 & \\
\hline
\end{tabular}

